\title{
Erzurum Kent Halkının Kış Aylarında Rekreasyonel Taleplerinin Belirlenmesi
}

\author{
Hasan YILMAZ* (i) Ayşegül AKSU (iD Sena Nur ANGIN \\ Atatürk Üniversitesi, Mimarlık ve Tasarım Fakültesi, Peyzaj Mimarlığı Bölümü, Erzurum, Türkiye \\ (*Sorumlu yazar e-mail: hyilmaz@atauni.edu.tr)
}

DOI: 10.17097/ataunizfd.516037

Geliş Tarihi (Received Date): 22.01.2019

Kabul Tarihi (Accepted Date): 21.05.2019

\begin{abstract}
Öz: Kentleşme hareketlerine bağlı olarak kentsel mekanlarda nüfus yoğunluğu giderek artmaktadır. Bu süreçte kentsel açık yeşil alanlar kent sağlı̆̆ı, kent ekolojisi ve kent estetĭgi açısından önem kazanmıştır. $\mathrm{Bu}$ alanların kentteki dağılımları, büyüklükleri, donatıları, estetik, ekolojik ve işlevsel özellikleri kadar yıl boyu kent halkına hizmet vermeleri de önemlidir. Erzurum kentinde kış ayları çok soğuk ve uzun olduğu için insanlar uzun süre kapalı mekanlarda yaşamak zorunda kalmaktadır. Bu durum kent merkezinde ve yakın çevresindeki rekreasyonel alanlara olan istekleri arttırmaktadır. Kent halkının dış mekan kullanımlarındaki seçimleri, bu alanlarda hangi rekreasyonel tesisleri istedikleri, alışveriş merkezlerine gidiş nedenleri, uygun dış mekan düzenlemelerinin olması durumunda mekan kullanım isteklerinin hangi yönde olacağı gibi eğilimleri belirlemek amacıyla bir anket çalışması yapılmıştır. Anketler Şubat ve Mart 2018 aylarında bire bir yapılmıştır. Yapılan araştırma sonucunda kent merkezindeki parkların yeterli olmadığı $(\% 78,8)$ sonucuna varılmıştır. Katılımcıların büyük çoğunluğu (\%86.4) kış aylarında dış mekanda yapacak çok fazla etkinlik olanağı olmadığı için alışveriş merkezlerini daha çok kullandıkları ortaya çıkmaktadır. Yaşam mekanları yakınında istenilen dış mekan alan kullanımlarına bakıldığında ise katılımcıların \%36.1'i park alanlarını ve \%23.1'i kışın kullanabilecekleri kapalı çocuk oyun alanları istenmektedir. Yapılan araştırma sonucunda kent parklarından özellikle kış aylarında da yararlanılmasına yönelik soğuk iklim bölgelerinde yıl boyu peyzajın kullanılabileceği yeni peyzaj tasarımlarına ihtiyaç duyulduğu fikri üzerinde durulmuştur.
\end{abstract}

Anahtar kelimeler: Erzurum kent parkları yeterliliği, Avm tercihleri, Dış mekan kullanım anketleri

\section{Determination of Recreational Demands of Erzurum City People in Winter}

\begin{abstract}
Population density is increasing in urban areas due to urbanization movements. In this process, urban green areas have gained importance in terms of urban health, urban ecology and urban aesthetics. It is also important that these areas serve for the city population all year long, as well as their distribution, size, equipment, aesthetics, ecological and functional characteristics. Since the winter months are long and extreme in Erzurum, people have to live in closed areas for a long time. This situation increases the demand for recreational areas in the city center and its surroundings. A survey was conducted in order to determine the tendencies in which the urban people used their outdoor uses, which recreational facilities they wanted in these areas, the reasons for going to shopping centers, the direction of use of space in case of appropriate outdoor arrangements. The surveys were conducted one by one in February and March 2018. As a result of the research, it was concluded that the parks in the city center were not sufficient $(78.8 \%)$. The majority of the participants $(86.4 \%)$ stated that they prefer shopping centers because there is not much activity to do outside in the winter months. $36.1 \%$ of the participants demand parking spaces near living spaces and $23.1 \%$ of them require indoor playgrounds for children to use in winter. As a result of the research, it was emphasized the necessity of the closed landscape parks in the cold climate regions for the use of urban parks especially in winter months.
\end{abstract}

Keywords: Erzurum city parks adequacy, Mall center preferences, Outdoor use surveys

\section{GíRis}

Kentleşme, dünya çapında hızla ilerlemekte ve insanlığın yarısından fazlası artık kentsel alanlarda yaşamaktadır. $\mathrm{Bu}$ oranın 2050 yılına kadar \%70'i geçmesi beklenmektedir (Heilig, 2012). Kırsal kesimden kent yaşantısına bu beklenmedik geçiş, doğal çevrelerle ve yeşil alanlar ile temas halinde kalmada önemli bir azalmaya sebep olmuştur (Skár and Krogh, 2009; Turner et al., 2004).

Yeşil alanlar, özellikle kentsel mekanlarda insanlar için vazgeçilmez sosyal ve psikolojik bir ihtiyaçtır. Yoğun kent yaşamında insanların serbest zamanlarını geçirebileceği ve günlük yaşamdan 
uzaklaşıp rahatlayabileceği açık mekanların, yeşil alanların ya da parkların varlığg sağlıklı bireylerin olması açısından büyük önem taşımaktadır (Baştürk, 2000).

Yapılan bilimsel araştırmalarda kentsel yeşil alanların ekolojik faydaları (Mcpherson, 1992; Nowak, 1994; Y1lmaz vd., 2008; Chen and Jim, 2010), çevresel faydaları (Boone et al., 2009; Kabisch and Haasea, 2014), rekreasyon faydaları (Talen and Anselin, 1998; Rigolon and Flohr, 2014), psikolojik faydalar1 (Yao et al., 2014; Mensah et al., 2016) ve ekonomik faydaları (Coolen and Meesters, 2012; Kabisch et al., 2015) olduğu ortaya konmuştur.

Çevresel yararlar arasında hava süzülmesi yoluyla yerel iklim kararlılığı (Gill et al., 2007; Jim and Chen, 2008; Bowler et al., 2010) yer almaktadır. Kentsel 1sı adası etkilerinin azalması açısından büyük önem taşımaktadır. Sokak ağaçlarının özel konumunun ve ortaya çıkan gölgenin genel enerji tüketimini azalttığı bulunmuştur (Simpson, 2002). Ayrıca yeşil alanlar gürültüyü azaltır (Bolund and Hunhammar, 1999; Özer vd., 2008), karbon depolamasını arttırır (Strohbach and Haase, 2012), yağmur suyu süzülmesi üzerinde olumlu etkileri vardır ve böylece su arıtmasını sağlamaktadır (Bolund and Hunhammar, 1999). Kentte yaşayanlar için sosyal yararlar arasında, yeşil alanların gerginliği azaltma ve rahatlama gibi zihinsel ve bedensel sağlik iyileştirmeleri yer almaktadır (Kuo et al., 1998; Maas et al., 2006; Konijnendijk et al., 2013). Yeşil alanlar sıcak havalarda yerel sıcaklıkları düşürerek biyoklimatik konforu artırırlar (Lafortezza et al., 2009; Y1lmaz ve Irmak, 2012; Breuste et al., 2013; Irmak et al., 2018). Aktif ve pasif faaliyetleri içeren rekreasyonel firsatlar sağlayarak yaşam kalitesini doğrudan artırabilmektedir (Byrne and Wolch, 2009). Buna ek olarak, yeşil alanlar güvenlik algısını da arttırırlar (Kuo et al., 1998). Yerel halkın buluşma yeri olarak sosyal etkileşimi desteklemektedir (Martin et al., 2004).

$\mathrm{Bu}$ yaralar göz önüne alındığında kentsel yeşil alanlar temel kamu hizmetleri olarak görülerek, kentin doğal ve kültürel özelliklerine göre planlama ve tasarımı dikkatlice ele alınmalıdır (Coolen and Meesters, 2012; Tian et al., 2014; Guzman et al., 2017; Xiao et al., 2017). Dikkat edilmesi gereken bir diğer husus da mevsimsel olarak yalnızca yazın değil, kış aylarında da yani insanların yıl boyu rekreasyon gereksinimini karşılayacak tasarımlar geliştirilmesidir.
Kış aylarında insanlar serbest zaman gereksinimlerini karşılamak için genellikle alışveriş merkezlerini kullanmaktadırlar. Özellikle kış mevsiminin uzun olduğu kentlerde kış kullanımına uygun olan yeni kentsel yeşil alan planlama ve tasarım yaklaşımlarına gereksinim vardır.

Doğu Anadolu Bölgesi, soğuk iklim koşullarının baskın olduğu, kış turizminin, hizmet sektörünün, tarım ve hayvancılığın öne çıktığı, nüfus yoğunluğunun daha çok kentsel mekanlarda toplandığı, çayır mera bitki örtüsünün ağırlık kazandı $\breve{g}_{1}$ bir peyzaj karakterine sahiptir. Kışların zor ve uzun olması insanların uzun süre kapalı mekanlarda yaşamak zorunda kalması nedeniyle kent merkezinde ve yakın çevresindeki etkinliğe açık veya kapalı rekreasyonel alanlarına olan gereksinimleri arttırmaktadır.

Doğu Anadolu Bölgesi'nin en önemli kentlerinden biri olan Erzurum kentinde son yıllarda dış mekan açık-yeşil alanlarının artırılmasına yönelik çalışmalara yer verilmektedir. Ancak bu alanlardaki rekreasyonel tesislerin tüm yıl boyunca halkın kullanımına olanak sağlaması bakımından yeterliliği tartışılabilir.

Bu araştırma, Erzurum kent halkının özellikle kış aylarındaki rekreasyonel istekleri, dış mekan açık yeşil alan kullanımları ve alışveriş merkezleri (Avm) tercih nedenlerini saptamak amacıyla yapılmıştır.

\section{MATERYAL VE METOT}

\section{Materyal}

Bu çalışma Erzurum kentinin farklı 3 noktasında bulunan, kış mevsiminde en fazla kullanılan ve kullanıcıların halkı temsil edeceği düşünülen 3 Avm'de yapılmıştır. Dolayısıyla çalışmanın ana materyalini bu Avm'lerdeki katılımcıların görüşleri oluşturmaktadır.

MÖ 4900 yıllarında kurulduğu tahmin edilen Erzurum Doğu Anadolu bölgesinin en büyük kentlerinden biridir. Erzurum'u da içine alan bölge tarih boyunca çeşitli kavim ve milletler tarafindan yönetilmiştir. Osmanlıların şehir ve çevresini 1514 yılında ele geçirmiştir ve Türkiye Cumhuriyeti'nin kurulduğu zamana kadar bu topraklarda hüküm sürmüşlerdir. Aynı zamanda 23 Temmuz 1919'da milli mücadele, milli birlik ve bağımsızlık hareketinin temelinin atıldığı kongre Erzurum'da toplanmıştır (Anonim, 2018a). 


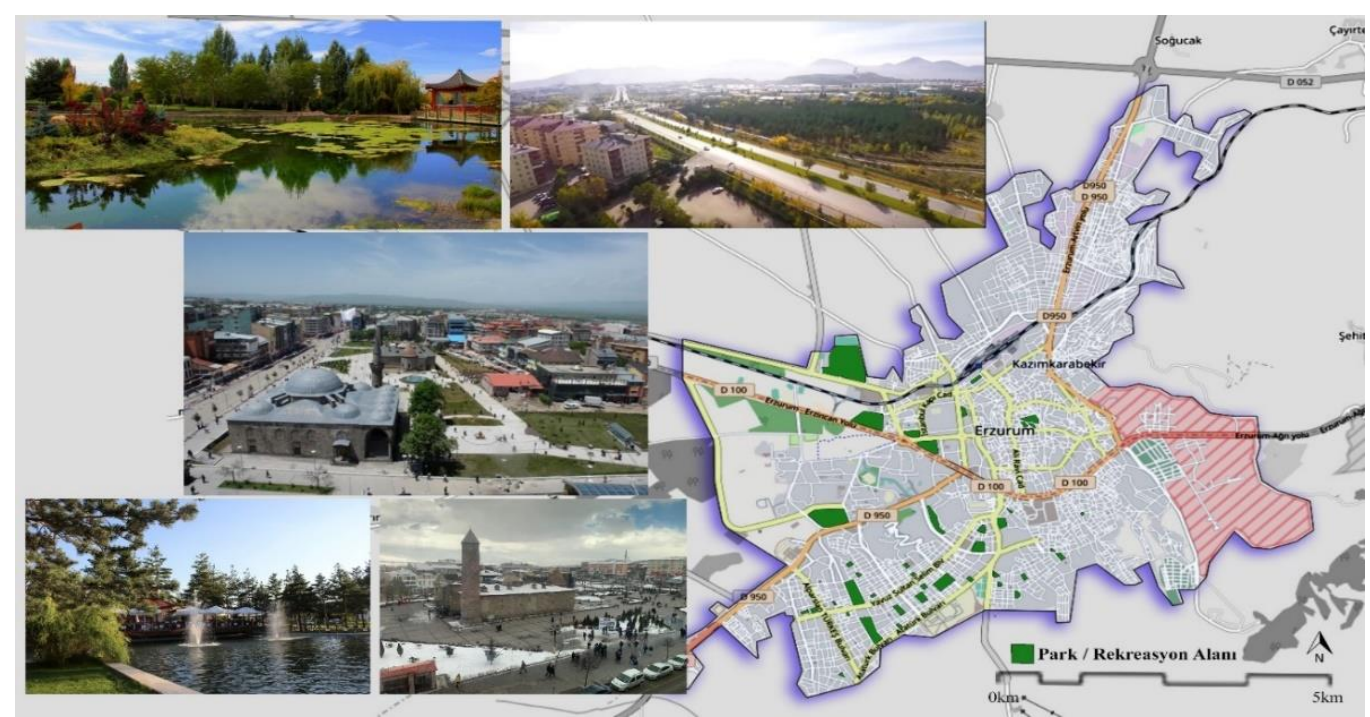

Şekil 1. Çalışma alanının konum haritası ve kentsel özellikleri

Erzurum ortalama $1950 \mathrm{~m}$ rakımda bulunmaktadır ve yüzölçümü $25.355 \mathrm{~km}^{2}$ olup, kent nüfusu yaklaşık 500 bin'dir. Ekstrem iklim şartlarına sahip yerleşim yerlerinden birisi olan kent, genelde soğuk iklimi simgeler (Şekil 1). En sıcak ay ortalaması $20.2^{\circ} \mathrm{C}$ olan kentin, yıllık ortalama sicaklığ $6^{\circ} \mathrm{C}$, en soğuk ay ortalaması $-8.3^{\circ} \mathrm{C}$ 'dir. Yağışlar düzensiz olup, yıllık yağış ortalaması $460.5 \mathrm{~mm}$ olarak kaydedilmiştir (Anonim, 2018b). Ayrica ilkbahar ve yaz mevsiminde en fazla yağışı alırken, en az yağışı kış mevsiminde alır. Genelde kışın yağışlar kar biçimindedir ve kar yağışlı gün sayıs1 50 gündür fakat 114 gün kadar yerde kalma süresi vardır (Anonim, 2018c).

Palandöken ve Konaklı kış turizm merkezleri, tarihi mekanları, termal kaplıca merkezleri çok sayıda yerli ve yabancı turisti ağırlamaktadır. Bölgede turizmin yanı sıra hizmet sektörü, tarım ve hayvancılık temel geçim kaynağıdır. Ayrıca bölgede 2 adet Devlet Üniversitesi, önemli devlet kurumlarının müdürlükleri ve Doğu Anadolu bölgesi için önemli büyük hastane/sağlık merkezleri bulunmaktadır.

\section{Metot}

Araştırmanın yöntemini sorun tanımlama, konu ile ilgili kaynak taraması, gözlem, anket çalışması, analiz ve değerlendirmesi oluşturmaktadır.
Erzurum kentinde yapılan gözlemlerde kent halkının özellikle kış aylarında Avm'lere yoğun ilgisinin olduğu, diş mekan açık-yeşil alanların kullanılmadığı belirlenmiştir. Kent halkının dış mekan kullanımlarındaki seçimleri, bu alanlarda hangi rekreasyonel tesisleri istedikleri, alışveriş merkezlerine gidiş nedenleri, uygun diş mekan düzenlemelerinin olması durumunda mekan kullanım isteklerinin hangi yönde olacağı gibi eğilimleri belirlemek amacıyla bir anket çalışması yapılmıştır. Anket kent merkezindeki Avm'lerde 1.5 aya yayılarak Şubat ve Mart 2018 tarihlerinde farklı saat ve günlerde yapılmıştır. Günlük \%1 ziyaretçi olasılığg göz önüne alınarak anket sayısı 150 kişi olarak belirlenmiş olup birebir yürütülmüştür. Anket sonuçları SPSS for Windows 22.00 istatistik programı ile analiz edilmiş ve sonuçlar şekil ve tablolarla verilmiştir.

\section{Bulgular}

Ankete Katılanların Bireysel Özellikleri

Ankete katılanların büyük çoğunluğunu (\%43) üniversite öğrencileri oluştururken, bunu \%22.1 ile memurlar izlemiştir. Katılımcıların \%63.3'ü kadın ve \%36.7'si erkektir(Şekil 2, 3).

Gelir durumlarına bakıldığında bin-2 bin TL arası gelire sahip olanlar $\% 37.3$ ve 5 bin TL üstü kazancı olanlar ise \%22.7 bulunmuştur (Şekil 3). 


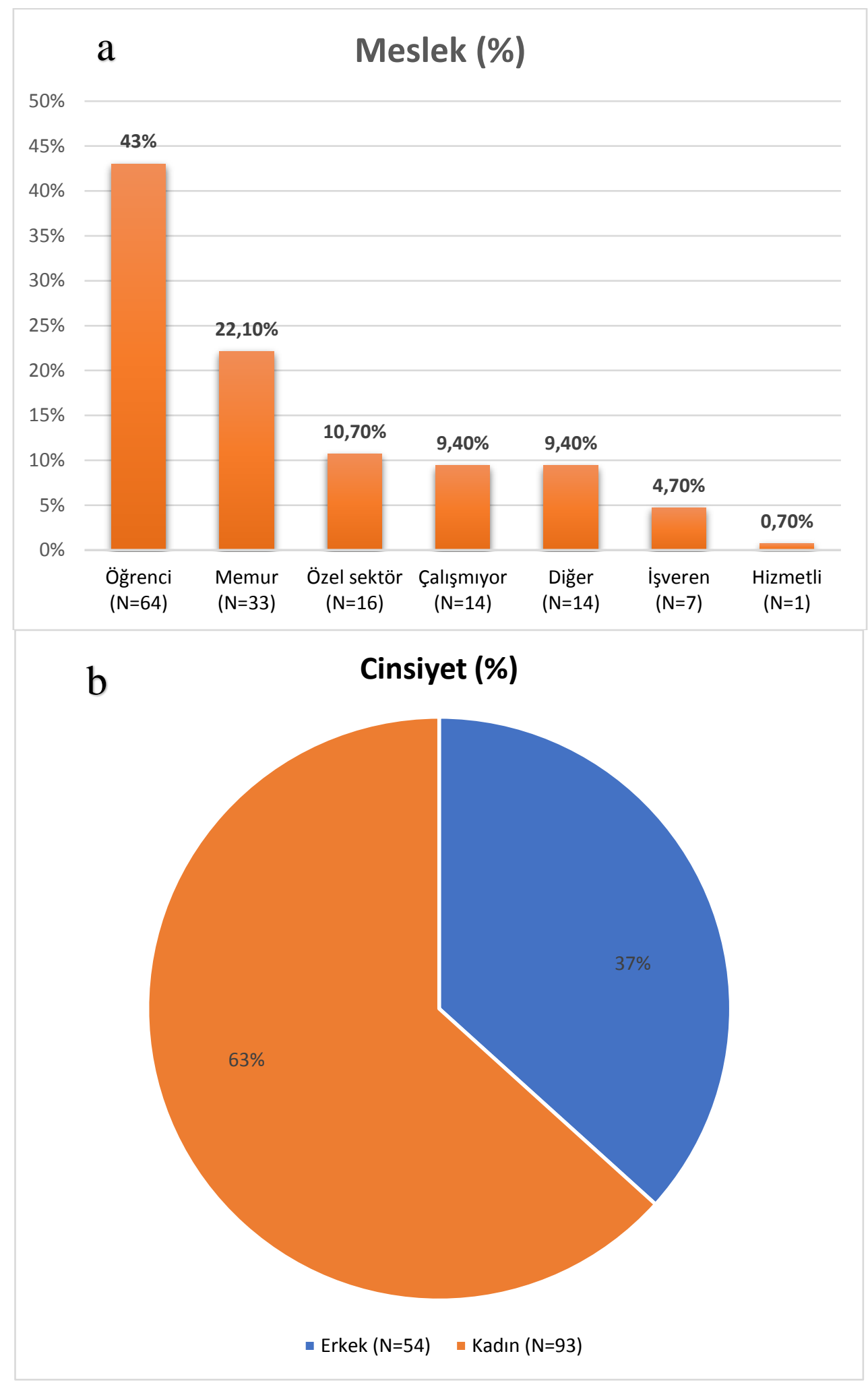

Şekil 2. Ankete katılanların özellikleri (a: meslek, b: cinsiyet) 


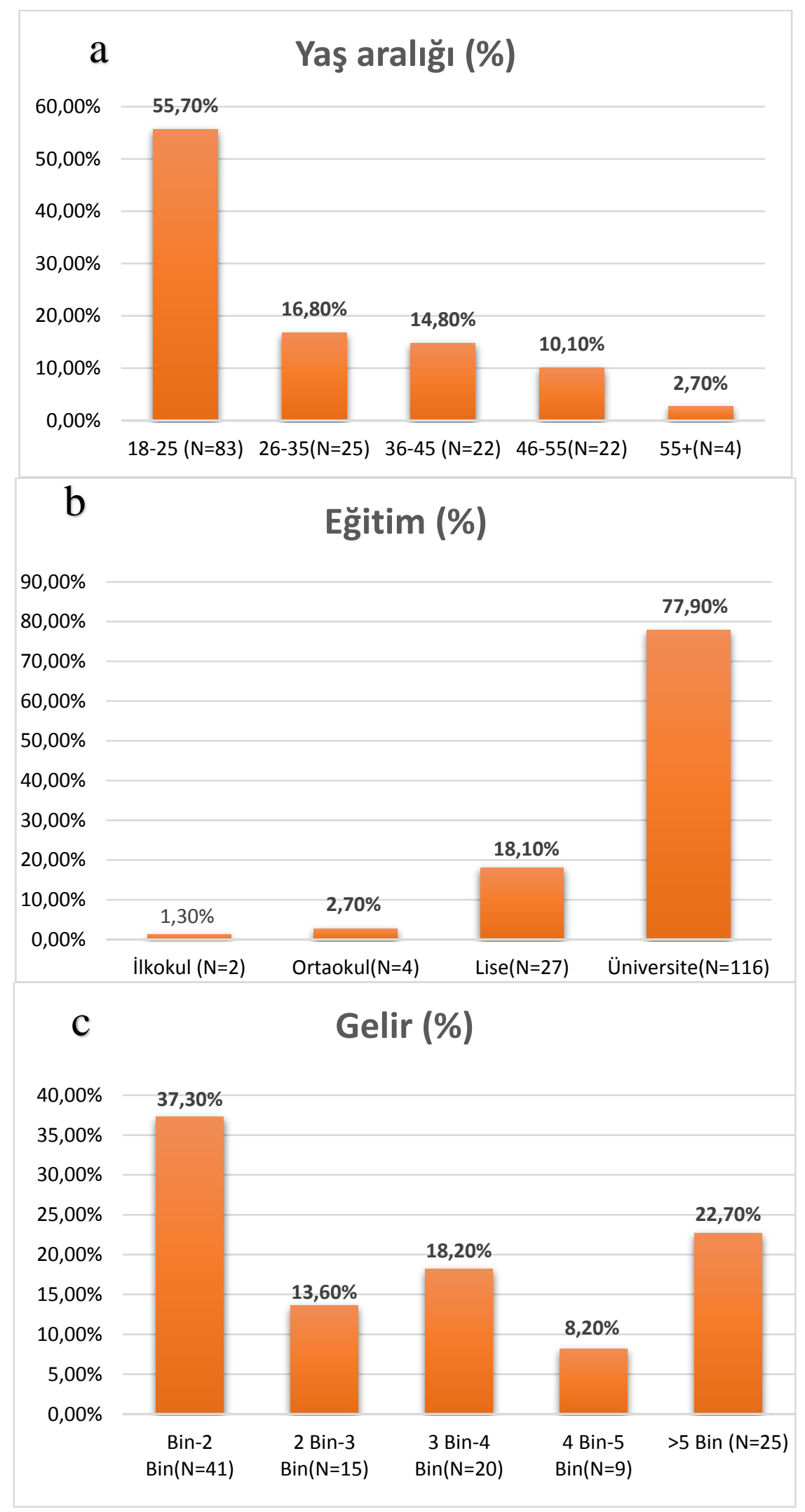

Şekil 3. Ankete katılanların yaş aralığı, eğitim ve gelir düzeyleri (a: yaş aralığı, b: eğitim c: gelir) 
Erzurum Kent Parklarının Yeterliliği ve Kullanım Sıklığı

Anket katılımcılarının \%78.8'i kent merkezindeki parkların yeterli olmadığını belirtmiştir. Kadınlar parkları \%80.6 yetersiz görürken, bu oran erkeklerde \%75.5'dir (Şekil 4).
Ankete katılanlar parkları en fazla haftada $1 \mathrm{kez}$ (\%26.5) kullanırken, büyük çoğunluğunun (\%55.8) parkları düzenli olarak kullanmadıkları belirlenmiştir. (Şekil 5).

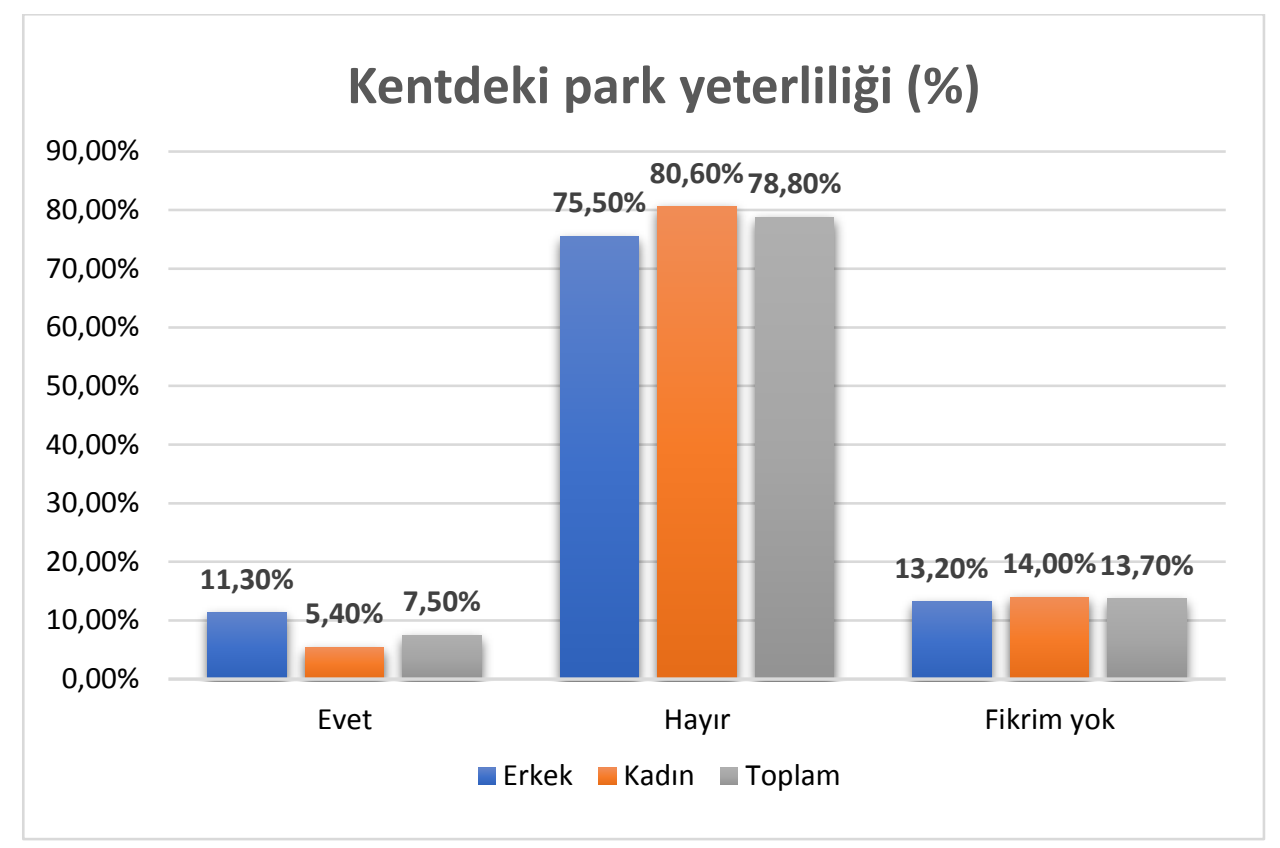

Şekil 4. Erzurum kent merkezindeki parkların yeterliliği konusunda katılımcı görüşleri

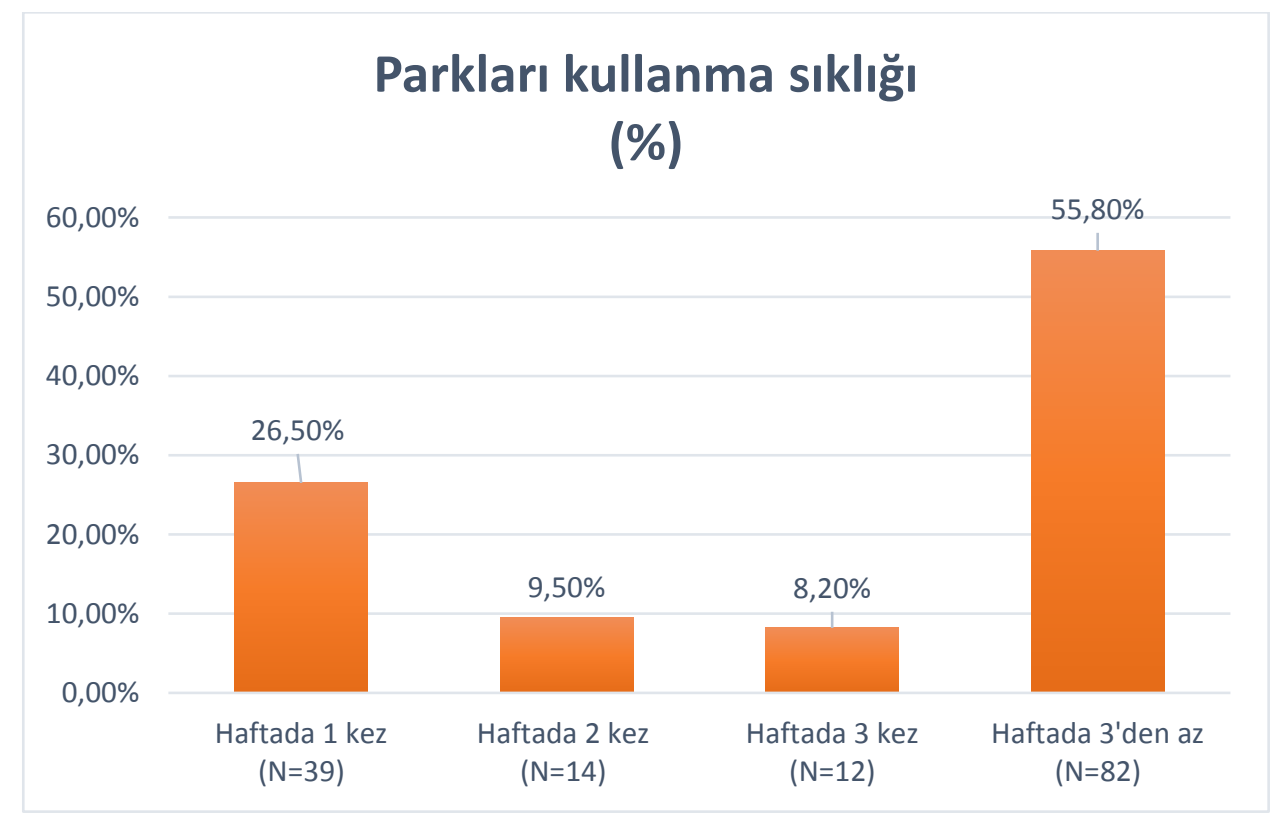

Şekil 5. Katılımcıların parkları kullanma sıklığı 
Katılımcıların Serbest Zaman Tercihleri

Yaz ve kış aylarında katılımcıların serbest zaman tercihleri belirlenmeye çalışılmıştır. Yaz aylarında katılımcıların \%22.3'ü evde oturmayı, \%16.7'si parklara gitmeyi ve \%16.7'si ilçelerde piknik yapmayı seçmişlerdir. Yaz aylarında insanlar daha çok dış mekanları kullandıkları ortaya çıkmaktadır. Katılımcıların çoğunluğunun öğrenci ve memur olmasından dolayı komşulara ve akrabalara ziyaret yapmadıkları görülmektedir (Şekil 6).

\section{Yaz aylarındaki serbest zaman tercihleri (\%)}

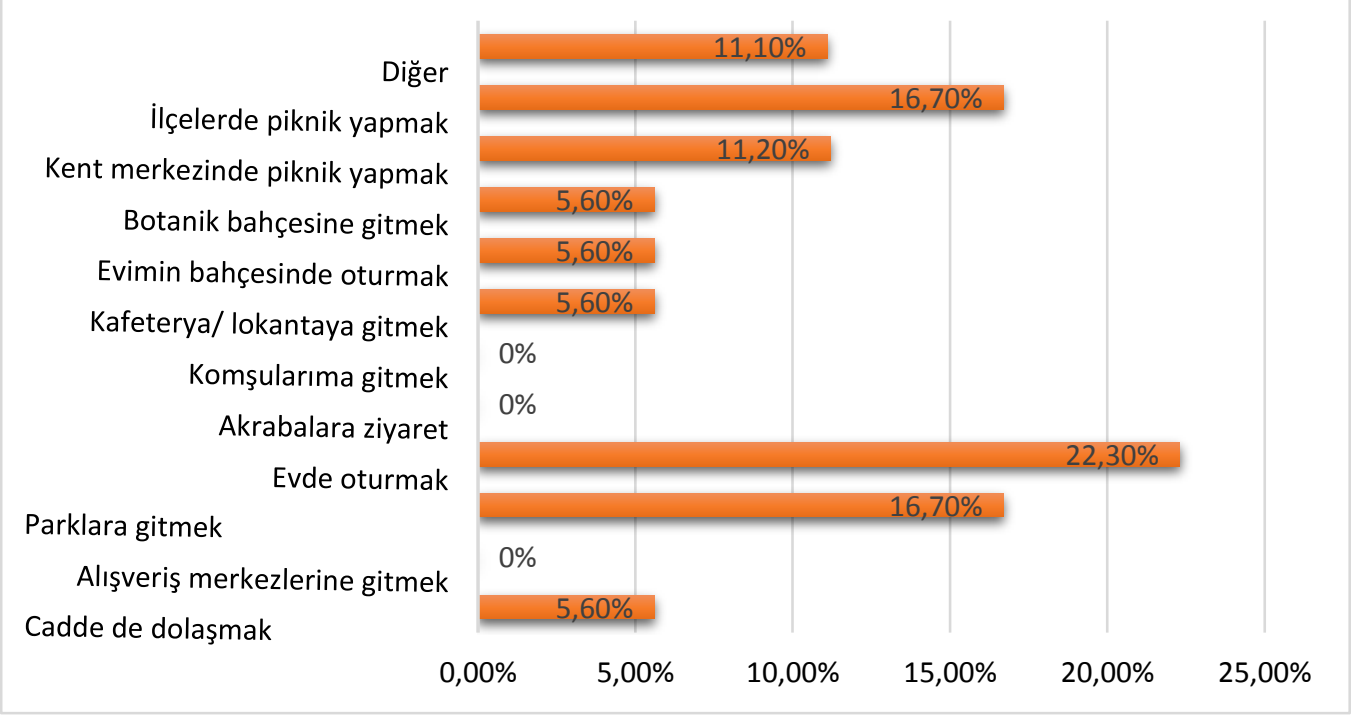

Şekil 6. Katılımcıların yaz aylarındaki serbest/boş zaman tercihleri

Kış aylarında ise katılımcıların \%33.4'ü alışveriş merkezine gitmek, \%22.3 evde oturmak tercihinde bulunulmuştur. Şekil 7'de görüldüğü üzere soğuk iklim bölgesinde yaşayan insanlar dışarıda bir süre geçirmek istediklerinde daha çok alışveriş merkezlerini yeğlemektedir.

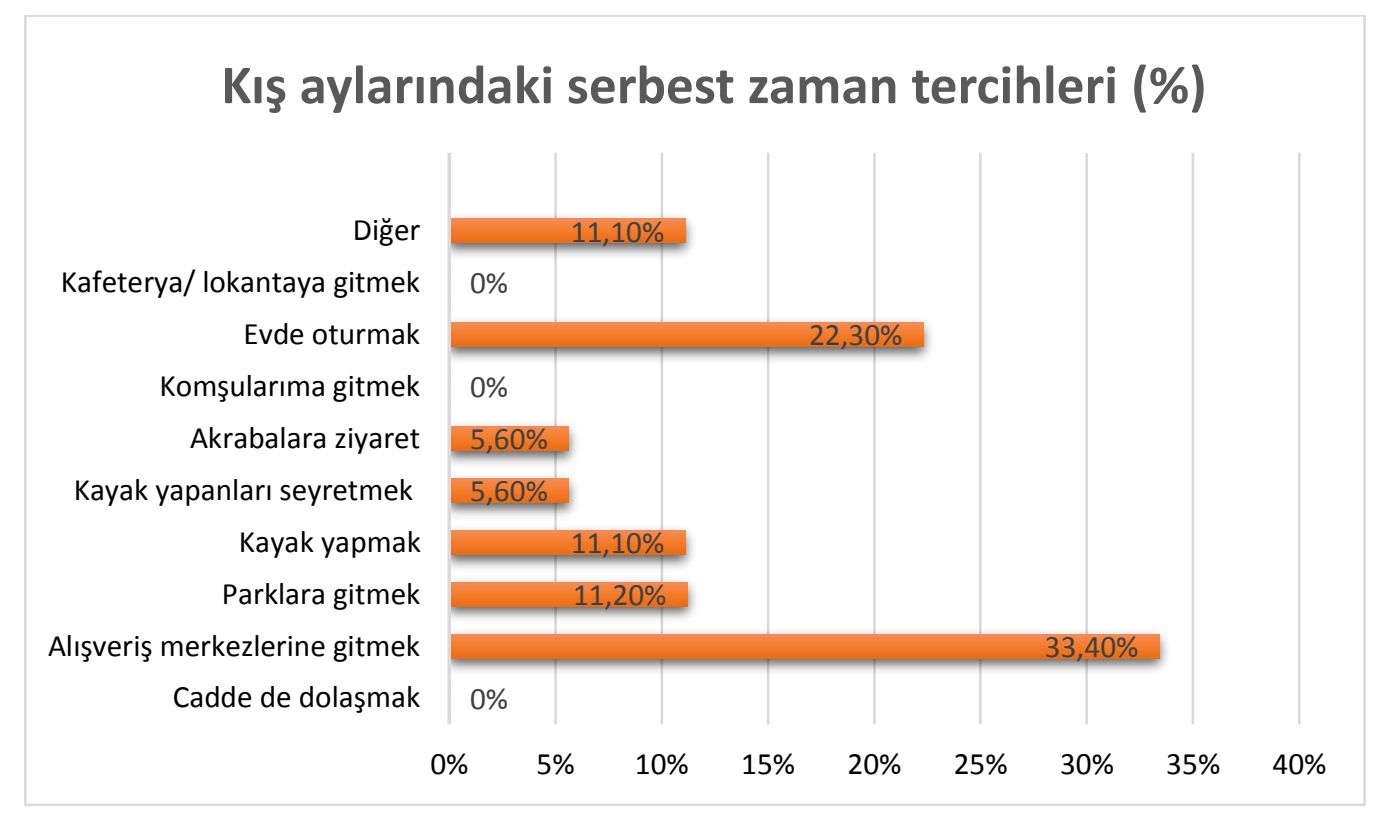

Şekil 7. Katılımcıların kış aylarında serbest zaman tercihleri 
Katılımcıların Alışveriş Merkezi Tercihleri

Alışveriş merkezlerini katılımcıların \%43'ü alışveriş, \%23.8,'i ise gezinti-vitrin incelemek için tercih ettikleri belirlenmiştir. $\mathrm{Bu}$ da soğuk iklim bölgelerinde insanların \%57'sinin alışveriş dışında dış mekan yerine yine de alışveriş merkezlerini tercih ettiklerini göstermektedir (Şekil 8).

Katılımcıların \%37.7'si alışveriş merkezlerini haftada $1 \mathrm{kez}$ tercih ederken, \%24.7'si ise haftada 2 kez tercih etmektedir (Şekil 9).

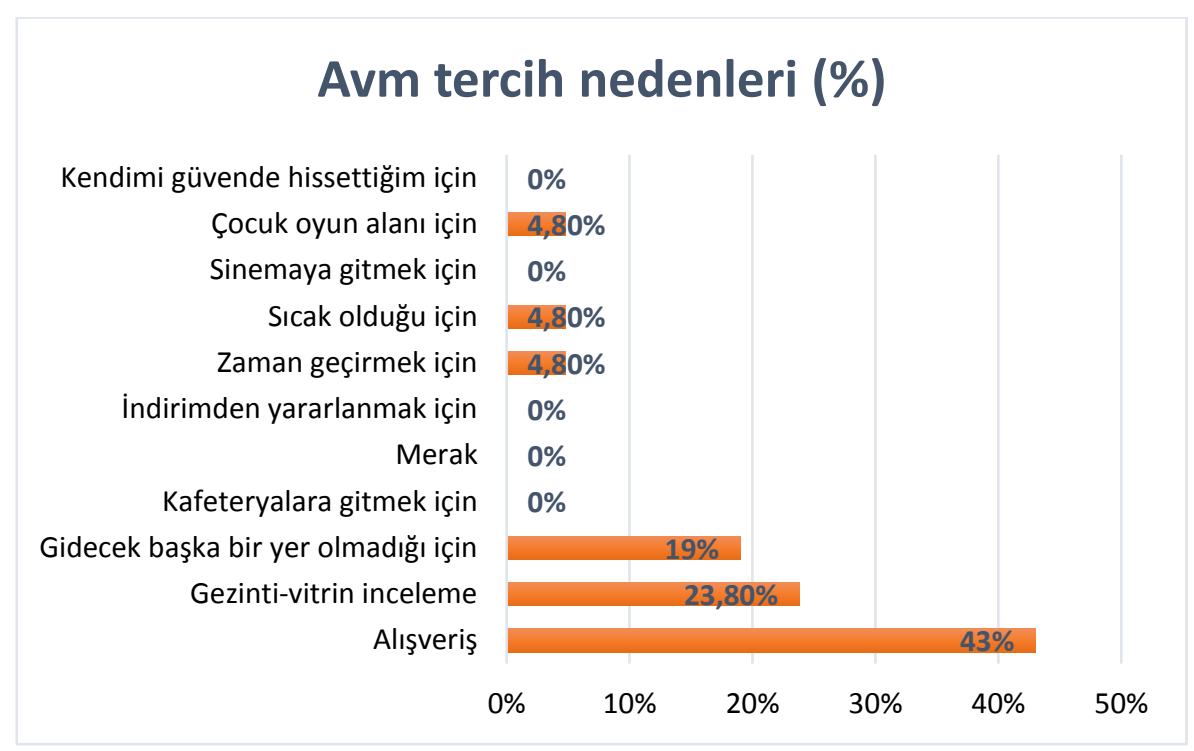

Şekil 8. Katılımcıların alışveriş merkezlerini tercih nedenleri

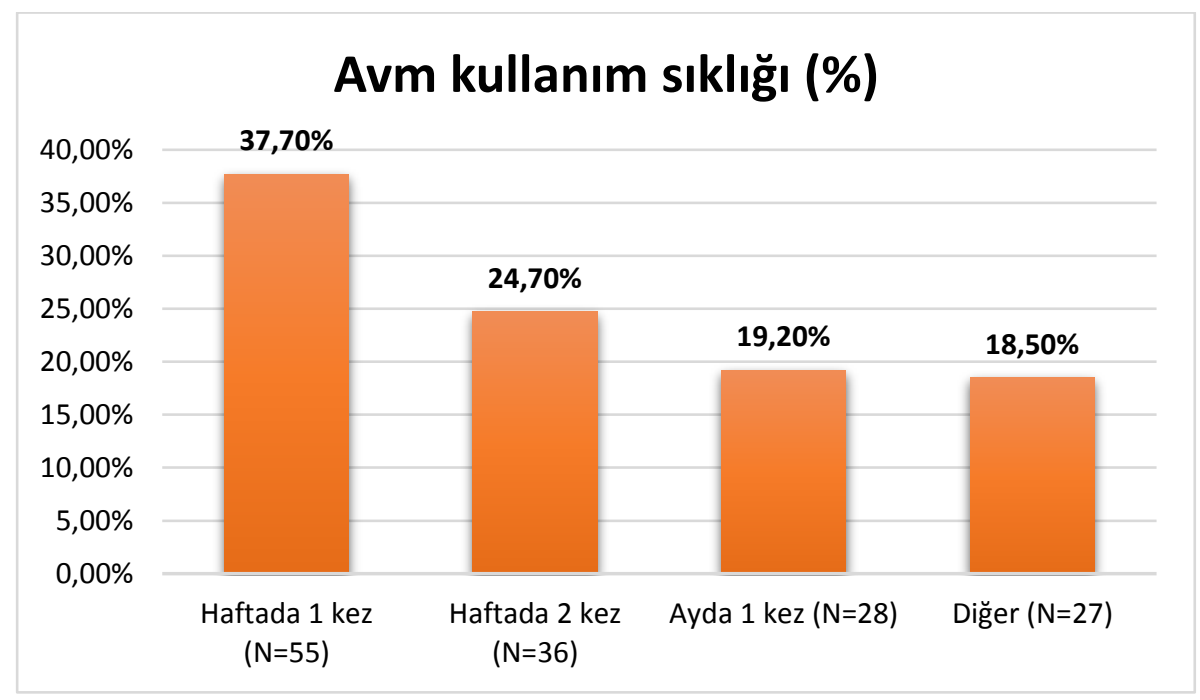

Şekil 9. Katılımcıların alışveriş merkezlerini kullanım sıklığı

Katılımcıların \%46.9'u alışveriş merkezlerine farklı zamanlarda ve \%36.1'i daha çok hafta sonu gittiklerini belirtmiştir. Katılımcıların \%36.1'i alışveriş merkezlerinde 1-2 saat geçirirken, \%35.4'ü 2-3 saat geçirdiklerini belirtmişlerdir. Katılımcıların büyük çoğunluğu (\%86.4) kış aylarında dış mekanda yapacak çok fazla faaliyet olmadığı için alışveriş merkezlerini seçtiklerini belirtmişlerdir. Erzurum kenti için yapılan bu çalışmada katılımcıların seçeneklerden alışveriş merkezlerini seçmeleri rekreasyonel tesislerin yetersizliğini ortaya koymuştur (Şekil 10). 


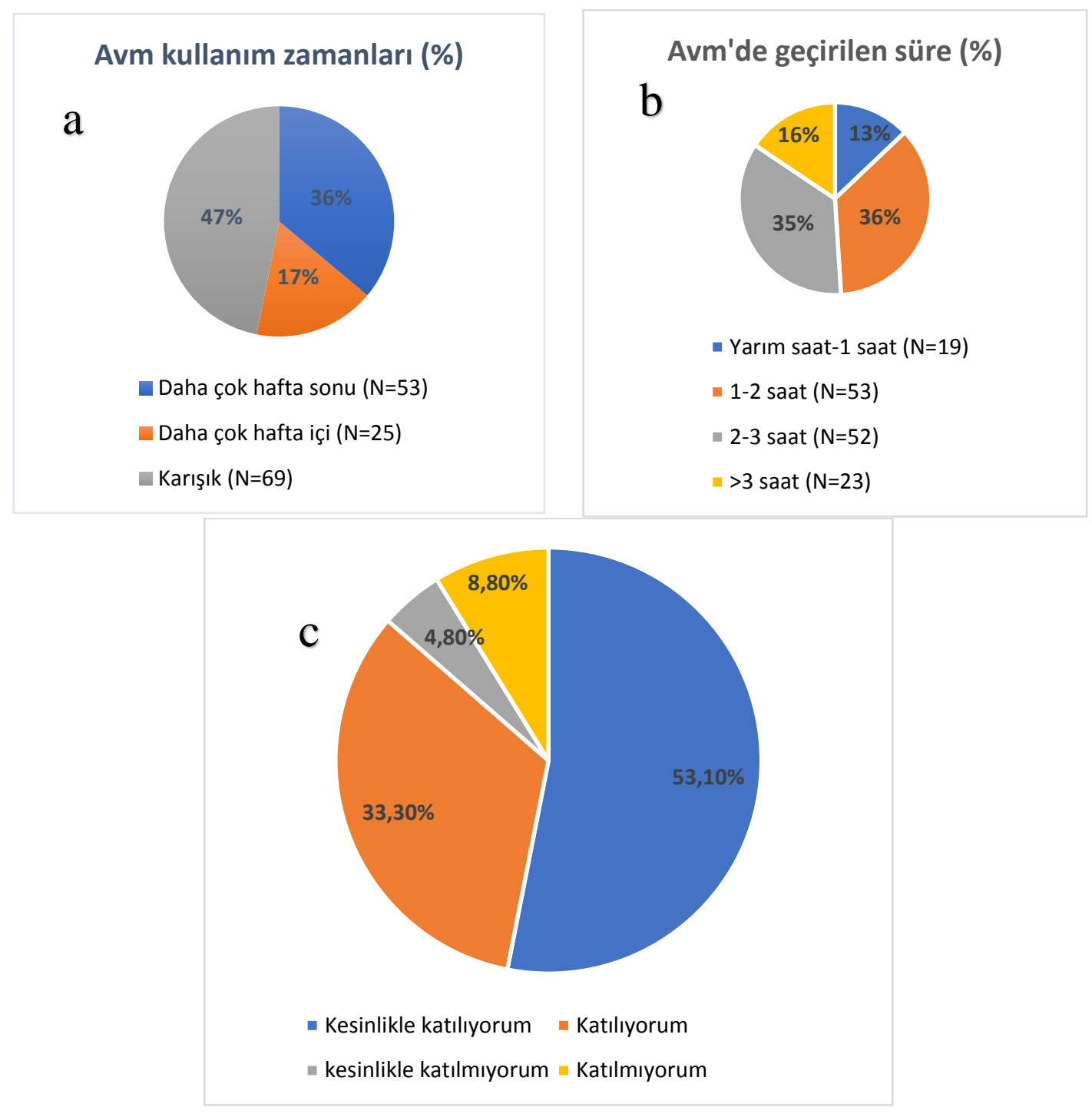

Şekil 10. Katılımcı tercihleri (a: Katılımcıların alışveriş merkezlerini kullanım zamanları b: Katılımcıların alışveriş merkezlerinde geçirdiği zaman geçirdiği zaman aralıkları c: Kış aylarında kent merkezinde seçenek olarak başka alan bulunmadığı için alışveriş merkezleri daha çok kullanılmak zorunda kalınmaktadır)

\section{Yaşam Mekanı Yakınında İstenen Dış}

Mekan Alan Kullanımları

Kent sakinleri yaşam mekanları çevresinde, \%36.1'i park alanlarını ve \%23.1'i kışın kullanabilecekleri kapalı çocuk oyun alanları istenmektedir. Bu durum soğuk iklim bölgesindeki insanların isteklerinin dışarıda zaman geçirebilecekleri mekanlar olduğunu göstermektedir (Şekil 11). 


\section{Mahallelerde öncelikli kullanım tercihleri(\%)}

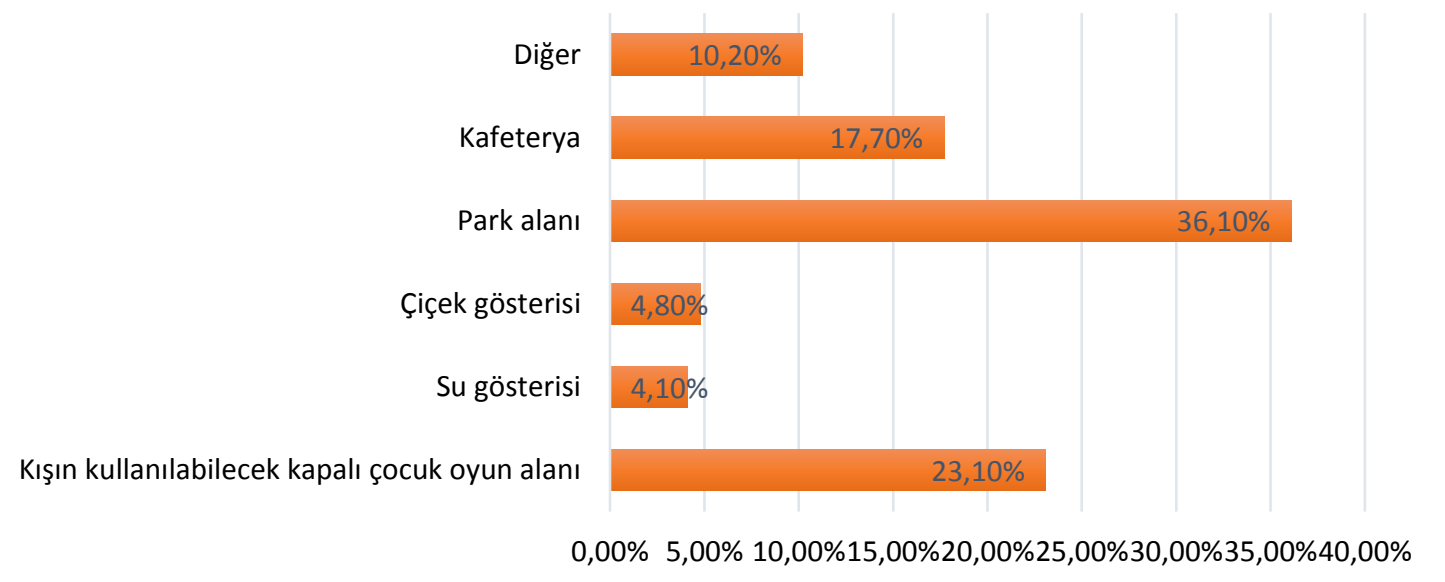

Şekil 11. Katılımcıların mahallelerindeki öncelikli tercihleri

Katılımcı Görüşlerinin İstatistik Yaklaşımı

Yapılan anketin istatistiki değerlendirilmesinde, sonucun anlamlı olabilmesi için pearson chi-square (ki-kare) değerindeki asymp.sig kısmı 0.05 'ten küçük olmalıdır. Bu anketin sonucunda anlamlı bulunan değerlerin analizi Tablo 1'de ve yaşa göre alışveriş merkezinde ne kadar zaman geçirdiklerinin dağılımı Şekil 12'de verilmiştir.

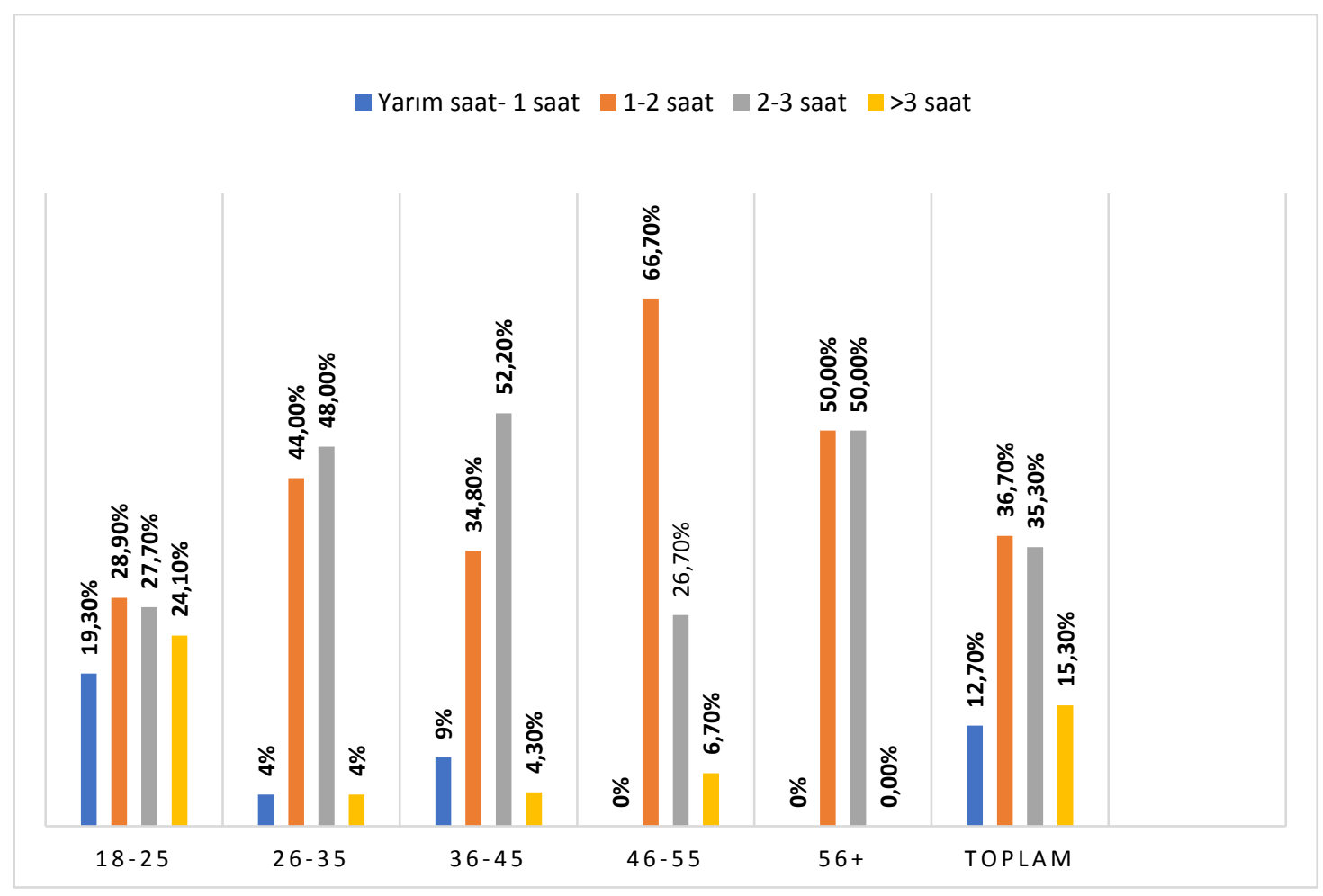

Şekil 12. Alışveriş merkezlerinde zaman geçirme aralı̆̆ının yaşa göre dağılımı 
Tablo 1. Alışveriş merkezlerinde zaman geçirme aralığının yaşa göre analizi

\begin{tabular}{|l|r|r|c|}
\hline \multicolumn{2}{l}{ Value } & df & $\begin{array}{c}\text { Asymp.Sig } \\
\text { (2-sided) }\end{array}$ \\
\hline Pearson Chi-Square (Ki-Kare) & $29,981^{\mathrm{a}}$ & 12 & 0,008 \\
\hline Likelihood ratio (olabilirlik oranı) & 30,467 & 12 & 0,002 \\
\hline Linear-by-linear association (doğrusal ilişki) & 0,337 & 1 & 0,562 \\
\hline N of Valid Cases (geçerli olgular) & 150 & & \\
\hline
\end{tabular}

Yapılan anketin analizinde pearson chi-square (ki-kare) değerindeki asymp.sig kısmı 0.05 'ten küçük olduğu için anlamlıdır. Bu anketin sonucunda anlamlı bulunan değerlerin analizi Tablo 2'de ve gelire göre alışveriş merkezlerinde zaman geçirme aralığı Şekil 13 'de verilmiştir.

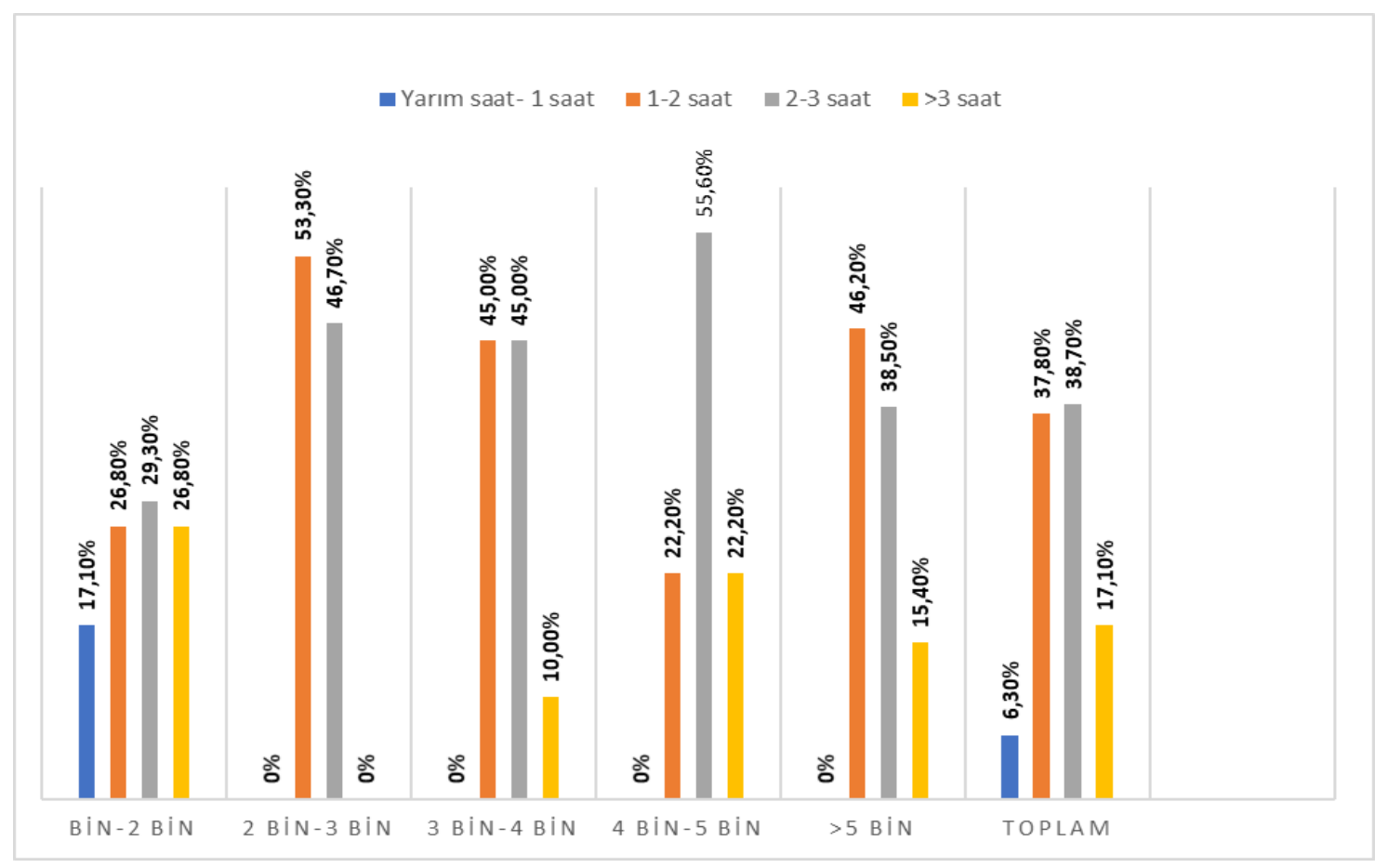

Şekil 13. Gelire göre alışveriş merkezlerinde zaman geçirme aralığ1

Tablo 2. Gelire göre alışveriş merkezlerinde zaman geçirme aralığı analizi

\begin{tabular}{|c|c|c|c|}
\hline & Value & df & $\begin{array}{l}\text { Asymp.Sig } \\
\text { (2-sided) }\end{array}$ \\
\hline Pearson Chi-Square (Ki-Kare) & $23,197^{\mathrm{a}}$ & 12 & 0,026 \\
\hline Likelihood ratio (olabilirlik oranı) & 27,596 & 12 & 0,006 \\
\hline Linear-by-linear association (doğrusal ilişki) & 0,328 & 1 & 0,567 \\
\hline $\mathrm{N}$ of Valid Cases (geçerli olgular) & \multicolumn{3}{|l|}{111} \\
\hline
\end{tabular}

\section{SONUÇ}

Anket sonuçlarına göre katılımcıların \%78.8'i kent merkezindeki parkların yeterli olmadığını belirtmiştir. Yaz aylarında serbest zaman isteklerine bakıldığında katılımcıların \%22.3'ü evde oturmayı, $\% 16.7$ 'si parklara gitmeyi ve \%16.7'si ilçelerde piknik yapmayı istedikleri belirlenmiştir. Sonuçlara göre yaz aylarında insanlar daha çok dış mekanları tercih etmektedir. Kış aylarındaki serbest zaman isteklerine bakıldığında ise katılımcıların \%33.4'ü alışveriş merkezine gitmek, \%22.3 evde oturmak tercihinde bulunulmuştur. Katılımcıların büyük çoğunluğu (\%86.4) kış aylarında dış mekanda yapacak çok fazla faaliyet olmadığı için alışveriş merkezlerine gittiklerini ifade etmişlerdir. Katılımcıların \%43'ünün alışveriş merkezlerini alışveriş yapmak için, 
\%23.8'inin ise gezinti-vitrin incelemek için Avm'yi kullandıkları belirlenmiştir. Yani soğuk iklim bölgelerinde insanların \%57'si alışveriş yapmadığı halde alışveriş merkezlerini kullanmaktadır. Çıkan sonuçlarda her ne kadar öğrenci sayısı fazla (\%43) olsa da ankete katılım isteği ve Avm'lerin kullanan kişilerin yoğunluğundan dolayı çalışmanın verileri ortaya konmuştur. Çalışmanın ilerlemesi açısından ev sakinlerine de anket yapılabilir. Fakat yaşanılan kentte çıplak gözle de kapalı peyzaj anlayışının benimsenmesi gerekliliği savunulmaktadır. Çünkü kapalı rekreasyon alanların eksikliği insanları alışveriş merkezlerinde zaman geçirmeye zorunlu bırakmaktadır. Yaşam mekanları yakınında istenilen dış mekan alan kullanımlarına bakıldığında ise katılımcıların \%36,1'i park alanlarını ve \%23.1'i kışın kullanabilecekleri kapalı çocuk oyun alanları istenmektedir. Erzurum kenti için yapılan bu çalışmada katılımcıların verdikleri cevaplar kış mevsiminde kullanılabilecek rekreasyonel tesislerin yetersizliğini ortaya koymuştur. Uzun kış mevsiminin hakim olduğu kentte özellikle kış aylarında kullanılabilecek rekreasyon alanlarına gerek vardır.

Yapılan bu araştırmada kışları uzun ve sert geçen kent merkezinde dış mekan açık yeşil alanlarının yıl boyunca kullanılabilecek donanımı bulunmadığı anlaşılmaktadır. Kış aylarında kapalı mekanda spor faaliyetlerine yönelik tesisler daha çok kamu kurumlarına ait olup, kış turizmine yönelik tesisler daha çok belirli bir ekonomik yapıdaki kent sakinlerince kullanılmaktadır. Ülkemizin en önemli kış turizm merkezlerinden birisi durumunda olan Palandöken Kayak Merkezi kentimizin rekreasyonel taleplerinden çok turizm ağırlıklıdır. Yerel yönetimlerin bu merkezde ve kent içinde dış mekan kullanımlarına yönelik yapmış olduğu çalışmalar olumlu olmakla beraber farklı ekonomik, sosyal ve kültürel yapıdaki kent sakinlerinin yıl boyu yararlanabileceği açık yeşil alanlara gereksinim vardır. Kolay erişilebilen, ucuz, konforlu, güvenli, her yaş ve cinsiyetten insanların kullanabileceği kamusal dış mekanlar yeni bir anlayışla ele alınmalıdır. Özellikle kentin bölgemizin en gelişmiş yerleşkelerinden biri olması, ana ulaşım koridoruna sahip olması, kış turizmi ile dünyaya açılması, sağlık ve eğitim merkezi durumunda olması, iklim şartları vb gibi kaynak değerleri göz önüne alındığında yeni açık yeşil alan planlama ve tasarımlarına gidilmelidir. Kış aylarında özellikle kent parklarına işlev kazandırmaya yönelik kapalı mekan peyzaj tasarımları kentte ön planda tutulmalıdır. Kentte marka değeri kazandıracak ve kent insanına tüm yıl boyunca rekreasyonel firsatlar sunacak büyük bir bölge parkı içerisinde iklim şartlarından etkilenilmeyecek ve her zaman kullanılabilecek peyzaj düzenlemelerine gidilmelidir. Böyle bir merkez aynı zamanda buz müzesi, buz sporları, biyoçeşitlilik müzesi, mini arboretum (bitki müzesi), lokal alışveriş ve geleneksel el sanatları müzesi, yeme-içme vb. ünitelerle desteklenmelidir. $\mathrm{Bu}$ alanın yapımında parasal kaynak sorunu aşılması durumunda sadece yılın kısa bir bölümünde kullanılan çok sayıda parklar yerine kent, bölge ve ülkede örnek oluşturabilme firsatı yakalanacaktır. Dünya'da bu tip kapalı rekreasyonel alanları bulunmaktadır (Eden Project) (Anonim, 2018d).

Sonuç olarak zor iklim şartlarının yaşandığı Erzurum gibi soğuk kent kimliği taşıyan kentsel mekanlarda dış mekan peyzaj düzenlemelerinde yeni yaklaşımlara gereksinim vardır. Dış mekan kullanımını bütün yıla yayma açısından özellikle de kış aylarında iklimi kontrol eden kış bahçeleri gibi kapalı peyzaj mekan düzenlemeleri maliyeti yüksek olmakla beraber iyi bir kış dostu peyzaj kullanımı olarak yararlı görülmektedir. $\mathrm{Bu}$ mekanlar aynı zamanda kentlerin marka değerlerini artırmada etkin rol üstlenebilirler. Sadece kent halkının rekreasyonel isteklerini karşılamakla kalmayıp, aynı zamanda kentin turizminin de çeşitlendirilmesine katkı sağlayacaktır.

\section{KAYNAKLAR}

Anonim 2018b. www.erzurum.bel.tr/IcerikDetayerzurum_tarihi/19/1.htlm (Erişim Tarihi: 15 Mart 2018)

Anonim, 2018a. https://www.arkeolojikhaber.com (Erişim Tarihi: 15 Mart 2018)

Anonim, 2018c. http://www.erzurumkulturturizm. gov.tr/TR-56063/cografya.html (Erişim Tarihi: 16 Mart 2018)

Anonim, 2018d. https://www.edenproject.com (Erişim Tarihi: 02 Nisan 2018)

Baştürk, Ö., 2000. Peyzaj tasarım kriterleri açısından, açık mekanlarda insan-çevre etkileşimi. İstanbul Teknik Üniv. Fen Bilimleri Enstitüsü, Yüksek Lisans Tezi, İstanbul, $120 \mathrm{~s}$.

Bolund, P., Hunhammar, S., 1999. Ecosystem services in urban areas. Ecological Economics, 29 (2): 293-301.

Boone, C.G., Buckley, G.L., Grove, J.M., Sister, C., 2009. Parks and people: An environmental justice inquiry in Baltimore, Maryland. Annals of the Association of American Geographers, 99 (4): 767-787.

Bowler, D.E., Buyung-Ali, L., Knight, T.M., Pullin, A.S., 2010. Urban greening to cool towns and cities: A systematic review of the empirical evidence. Landscape and urban planning, 97 (3): 147-155.

Breuste, J., Haase, D., Elmqvist, T., 2013. Urban landscapes and ecosystem services. Ecosystem services in agricultural and urban landscapes, 83104.

Byrne, J., Wolch, J., 2009. Nature, race, and parks: past research and future directions for 
geographic research. Progress in Human Geography, 33 (6): 743-765.

Chen, W. Y., Jim, C.Y., 2010. Resident motivations and willingness-to-pay for urban biodiversity conservation in Guangzhou (China). Environmental management, 45 (5): 1052-1064.

Coolen, H., Meesters, J., 2012. Private and public green spaces: meaningful but different settings. Journal of Housing and the Built Environment, 27 (1): 49-67.

Gill, S.E., Handley, J.F., Ennos, A.R., Pauleit, S., 2007. Adapting cities for climate change: the role of the green infrastructure. Built environment, 33 (1): 115-133.

Guzman, L.A., Oviedo, D., Rivera, C., 2017. Assessing equity in transport accessibility to work and study: The Bogotá region. Journal of Transport Geography, 58: 236-246.

Heilig, G.K., 2012. World Urbanization Prospects: The 2011 Revision. New York: United Nations, Department of Economic and Social Affairs (DESA), Population Division, Population Estimates and Projections Section.

Irmak A., Yilmaz S., Mutlu E., Yılmaz H., 2018. Assessment of the effects of different tree species on urban microclimate. Environmental Science and Pollution Research, 25 (16): 1580215822.

Jim, C.Y., Chen, W.Y., 2008. Assessing the ecosystem service of air pollutant removal by urban trees in Guangzhou (China). Journal of Environmental Management, 88 (4): 665-676.

Kabisch, N., Haase, D., 2014. Green justice or just green? Provision of urban green spaces in Berlin, Germany. Landscape and Urban Planning, 122: 129-139.

Kabisch, N., Qureshi, S., Haase, D., 2015. Humanenvironment interactions in urban green spacesA systematic review of contemporary issues and prospects for future research. Environmental Impact Assessment Review, 50: 25-34.

Konijnendijk, C.C., Annerstedt, M., Nielsen, A.B., Maruthaveeran, S., 2013. Benefits of urban parks. A systematic review. A Report for IFPRA.

Kuo, F.E., Bacaicoa, M., Sullivan, W.C., 1998. Transforming inner-city landscapes: Trees, sense of safety, and preference. Environment and Behavior, 30 (1): 28-59.

Lafortezza, R., Carrus, G., Sanesi, G., Davies, C., 2009. Benefits and well-being perceived by people visiting green spaces in periods of heat stress. Urban Forestry \& Urban Greening, 8 (2): 97-108.

Maas, J., Verheij, R.A., Groenewegen, P.P., De Vries, S., Spreeuwenberg, P., 2006. Green space, urbanity, and health: how strong is the relation?.
Journal of Epidemiology \& Community Health, 60 (7): 587-592.

Martin, C.A., Warren, P.S., Kinzig, A.P., 2004. Neighborhood socioeconomic status is a useful predictor of perennial landscape vegetation in residential neighborhoods and embedded small parks of Phoenix, AZ. Landscape and Urban Planning, 69 (4): 355-368.

McPherson, E.G., 1992. Accounting for benefits and costs of urban greenspace. Landscape and Urban Planning, 22 (1): 41-51.

Mensah, C.A., Andres, L., Perera, U., Roji, A., 2016. Enhancing quality of life through the lens of green spaces: A systematic review approach. International Journal of Wellbeing, 6 (1): 142163.

Nowak, D.J., 1994. Air pollution removal by Chicago's Urban forest, In: McPherson, E.G, D.J, Nowak and R. A. Rowntree. Chicago's Urban Forest Ecosystem: Result of the Chicago's Urban Forest Climate Project, USDA Forest Service General Technical Report, NE-186: 6381.

Özer, S., Irmak, M.A., Y1lmaz, H., 2008. Determination of roadside noise reduction effectiveness of Pinus slyvestris L. and Populus nigra L. in Erzurum, Turkey. Environmental Monitoring and Assessment, 144 (1-3): 191-197.

Rigolon, A., Flohr, T.L., 2014. Access to parks for youth as an environmental justice issue: access inequalities and possible solutions. Buildings, 4 (2): 69-94.

Simpson, J.R., 2002. Improved estimates of tree-shade effects on residential energy use. Energy and Buildings, 34 (10): 1067-1076.

Skár, M., Krogh, E., 2009. Changes in children's nature-based experiences near home: From spontaneous play to adult-controlled, planned and organised activities. Children's Geographies, 7 (3): 339-354.

Strohbach, M.W., Haase, D., 2012. Above-ground carbon storage by urban trees in Leipzig, Germany: Analysis of patterns in a European city. Landscape and Urban Planning, 104 (1): 95104.

Talen, E., Anselin, L., 1998. Assessing spatial equity: an evaluation of measures of accessibility to public playgrounds. Environment and Planning A, 30 (4): 595-613.

Tian, Y., Jim, C.Y., Wang, H., 2014. Assessing the landscape and ecological quality of urban green spaces in a compact city. Landscape and Urban Planning, 121: 97-108.

Turner, W.R., Nakamura, T., Dinetti, M., 2004. Global urbanization and the separation of humans from nature. Bioscience, 54 (6): 585 590. 
Xiao, Y., Wang, Z., Li, Z., Tang, Z., 2017. An assessment of urban park access in ShanghaiImplications for the social equity in urban China. Landscape and Urban Planning, 157: 383-393.

Yao, L., Liu, J., Wang, R., Yin, K., Han, B., 2014. Effective green equivalent-A measure of public green spaces for cities. Ecological indicators, 47: 123-127.
Yılmaz, H., Irmak, M.A., 2012. Yerleşke Planlamasında Bitkisel Tasarım Illkeleri; Atatürk Üniversitesi Yerleşkesi Örneği. Atatürk Üniv. Yayınları, No:1011, Erzurum, $192 \mathrm{~s}$.

Yilmaz, H., Yildiz, N.D., Yilmaz, S., 2008. Effects of snow-reflected light levels on human visual comfort. Environmental Monitoring and Assessment, 144 (1-3): 367-375. 